\title{
Pattern of facial palsy in a typical Nigerian specialist hospital
}

\author{
*Lamina S ${ }^{1}$, Hanif $S^{2}$
}

1. Department of Biomedical Technology, School of Health Technology, Federal University of Technology, Owerri, Nigeria

2. Department of Physiotherapy, Bayero University, Kano, Nigeria

\begin{abstract}
Background: Data on incidence of facial palsy is generally lacking in Nigeria.

Objective: 'To assess six years' incidence of facial palsy in Murtala Muhammed Specialist Hospital (MMSH), Kano, Nigeria. Method: The records of patients diagnosed as facial problems between January 2000 and December 2005 were scrutinized. Data on diagnosis, age, sex, side affected, occupation and causes were obtained.

Results: A total number of 698 patients with facial problems were recorded. Five hundred and ninety four (85\%) were diagnosed as facial palsy. Out of the diagnosed facial palsy, males (56.2\%) had a higher incidence than females; 20-34 years age group (40.3\%) had a greater prevalence; the commonest cause of facial palsy was found out to be Idiopathic (39.1\%) and was most common among business men (31.6\%). Right sided facial palsy $(52.2 \%)$ was predominant. Incidence of facial palsy was highest in 2003 (25.3\%) and decreased from 2004.

Conclusion: It was concluded that the incidence of facial palsy was high and Bell's palsy remains the most common causes of facial (nerve) paralysis.

Key words: Incidence, facial palsy, Bell's palsy, Nigeria

African Health Sciences 2012; (4): 514 - 517 http://dx.doi.org/10.4314/ahs.v12i4.18
\end{abstract}

\section{Introduction}

When we think of facial paralysis, we often think of weak muscles and a drooping face. Facial palsy/ paralysis is a condition in which there is a lesion of the facial nerve. It imposes great psychological and social problems on the individual with the condition 1.

The facial nerve has a very important function; it supplies all the muscles of facial expression and is responsible for those movements that we take for granted such as smiling, frowning, lifting the eyebrows, closing the eyes and moving the lips and cheeks. Facial paralysis has been primarily considered a cosmetic inconvenience with associated functional problems. As human beings, our primary form of non-verbal communication relies upon minute changes in facial expression that reveal our innermost feelings. Just as an aphasic person cannot communicate verbally after a stroke, the patient with facial paralysis cannot convey the normal social signals of inter-personal communication ${ }^{2}$.

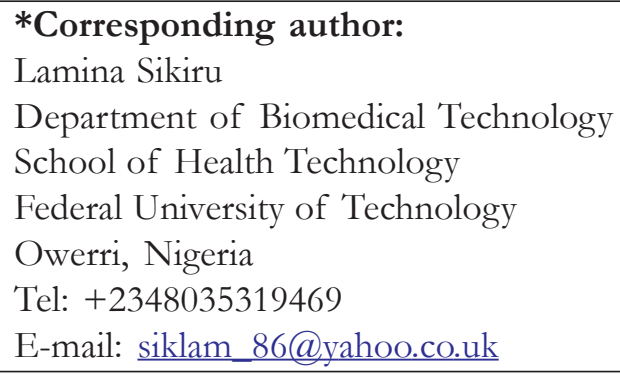

Data on the incidence of facial palsy has been collected in several developed countries ${ }^{2-4}$ but are lacking in third world particularly Nigeria. Foreign data may not be relevant or helpful for Nigeria as it may be an under- or overestimate of Nigeria situation. This dearth of data in Nigeria served as impetus for this study. Therefore the purpose of the present study was to determine the prevalence of facial palsy and its causes. It is belief that the outcome of the present study will help in the prevention and management of the condition through sensitization. Furthermore, the outcome of this study will provide the much more needed baseline data, which other studies could be based on.

\section{Method}

This study was carried out in Murtala Mohammad Specialist Hospital (MMSH), Kano, North-west Nigeria. The hospital was established in 1927 and has been the solely core hospital serving patients from both metropolitan and rural areas as well as some neighboring states (Bauchi, Jigawa, Katsina and Kaduna) and some nearby foreign countries such as Niger and Cameroon. The hospital also serves as a referral centre for other established government hospitals and private health establishments within and outside the state.

African Health Sciences Vol 12 Issue 4 December 2012 
A six years retrospective study was conducted between January 2000 and December 2005. The records of patients diagnosed by appropriate medical personnel as having facial problems during the period of six years (2000-2005) were obtained from the medical records department of the hospital. Data obtained from the patients' files included diagnosis, age, sex, occupation, side affected and cause.

Descriptive and inferential statistics were used to analyze data. All statistical analysis was performed using the Statistical Package for the Social Sciences (SPSS) (Windows Version 16.0, Chicago, IL, U.S.A.). All tests were performed at an alpha level of 0.05 to indicate statistical significance.

\section{Results}

A total number of 698 cases with facial problems were recorded, out of which 594 (85\%) were diagnosed as facial palsy. The case reports of patients diagnosed as facial palsy were further scrutinized. Their mean age was $33.39 \pm 15.71$; males, 334 $(56.2 \%)$ were found to be having higher incidence of facial palsy than females, 260 (43.8\%). Table 1 shows the age distribution of the patients based on the classification by Hawley ${ }^{5}$. The middle age subcategory (20-34yrs) had the highest incidence of facial palsy $(240[40.3 \%])$, while the old-age category (65yrs and above) had the least (20 [3.7\%]) incidence. Out of the 594 cases, $310(52.2 \%)$ had right sided facial palsy; $274(46.1 \%)$ had left sided facial palsy, and very few $10(1.7 \%)$ had bilateral facial palsy. Age, gender and occupation significantly associated with the incidence of facial palsy at $\mathrm{p}<0.05$ (table 2).

Table 1: Age distribution of patients with facial palsy

\begin{tabular}{llr}
\hline Age(years) & Frequency & $\begin{array}{r}\text { Percent } \\
(\%)\end{array}$ \\
\hline $0-12$ & 40 & 6.7 \\
$13-19$ & 40 & 6.7 \\
$20-34$ & 240 & 40.3 \\
$35-44$ & 124 & 20.8 \\
$45-64$ & 130 & 21.8 \\
$65-74$ & 14 & 2.3 \\
$75-84$ & 4 & 1.1 \\
$>85$ & 2 & 0.3 \\
Total & $\mathbf{5 9 4}$ & $\mathbf{1 0 0 . 0}$ \\
\hline
\end{tabular}

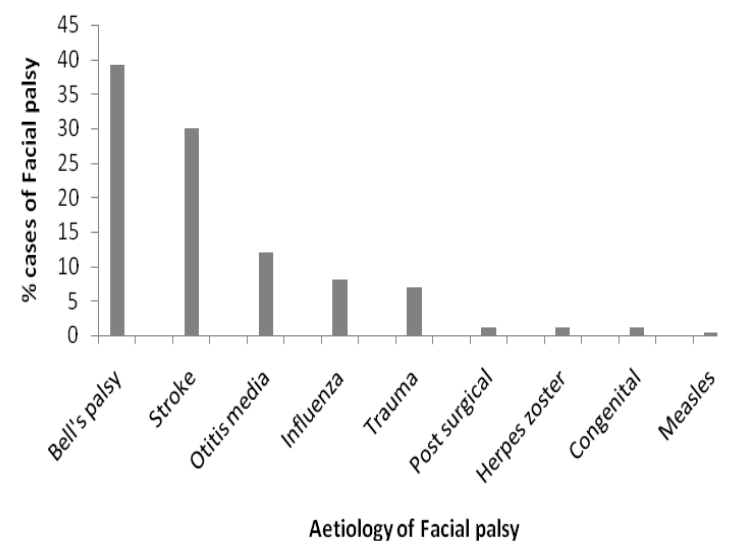

Figure 1: Aetiological incidence of facial palsy

The commonest cause of facial palsy was idiopathic accounting for 232 (39.1\%), followed by stroke 178 $(30.0 \%)$ and least was measles with $2(0.3 \%)$ (figure 1). Figure 2 shows the incidence of facial palsy which was highest among business men, 188 (31.6\%) followed by housewives, $134(22.6 \%)$ and least among medical personnel, 2 (0.3\%).

Incidence of facial palsy increased from year 2000 to 2003 (60 [10.1\%] in 2000; 82 [13.8\%] in 2001; 134 [22.6\%] in 2002; 150 [25.3\%] in 2003). There was a decrease afterwards (80 [13.5\%] in 2004 and $88[14.8 \%]$ in 2005).

Table 2: Associated factors and incidence of facial palsy (Chi square $\left[\mathrm{X}^{2}\right]$ )

\begin{tabular}{llcc}
\hline Variables & df & $\mathrm{X}^{2}$-value & p-value \\
\hline $\begin{array}{l}\text { Gender and incidence } \\
\text { of facial palsy }\end{array}$ & 1 & 9.219 & $0.002^{*}$ \\
$\begin{array}{l}\text { Age group and incide- } \\
\text { nce of facial palsy }\end{array}$ & 7 & 662.458 & $0.000^{*}$ \\
$\begin{array}{l}\text { Occupation and incide- } \\
\text { nce of facial palsy }\end{array}$ & 467.515 & $0.001^{*}$ \\
\hline $\mathrm{p}<0.05 \quad *$ significant & & & \\
\hline
\end{tabular}




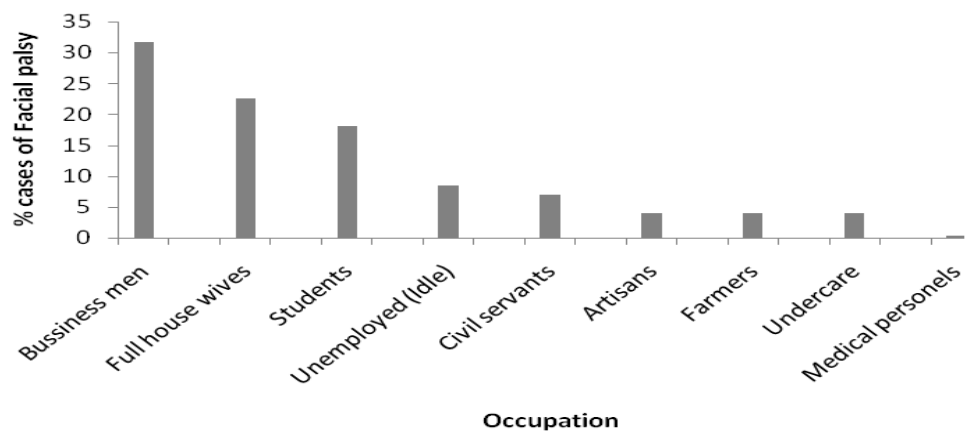

Figure 2: Occupational incidence of facial palsy

\section{Discussion}

The present study revealed the most prevalent age group, sex, occupation, side affected and cause among facial palsy patients in North-west, Nigeria. Incidence of facial palsy was highest in 2003 and decreased from 2004.Generally, the incidence of facial palsy was high $(85 \%)$.

The incidence of facial palsy is slightly higher in males than females as reported in the present study. This is contrary to the work of Holland and Weiner ${ }^{6}$ in UK, Savetteiri ${ }^{3}$ in two Sicilian municipalities and Nicoletti ${ }^{4}$ in Cordillera province, Bolivia, and several other similar studies ${ }^{7-12}$ reported equal incidence facial palsy in both genders. Reasons for the present finding on gender might not be unconnected to the activity level; males being more active could be more exposed to trauma and environmental hazard and females being mostly full time housewives and mostly in doors in the Northern part (Kano state) of Nigeria, have less exposure to trauma and unfavorable environmental conditions.

In the present study, facial palsy was most frequently encountered among the middle age category; this finding is similar to that of several other studies $7,8,9,13,14$. The incidence in the present study decreased with age which is contrary to the several reports ${ }^{3,4,15}$ that incidence increased with. It was also found in the present study that the business men had the highest incidence of facial palsy; the reason could be linked to the fact that they are most mobile and active and have high incidence of exposure to trauma and different unfavorable environmental conditions.

The right side of the face had a higher incidence than the left which is similar to that of Ahmed ${ }^{16}$. This result is contrary to that reported by Al Ghamdi ${ }^{7}$ who reported a higher incidence of left facial palsy than the right side and no single bilateral incidence of facial palsy. The reason for higher incidence of right sided facial palsy in the present study could be linked to the fact that most people are right handed ${ }^{17}$, making use of the body which could predispose them to right side injury particularly, during fall in trauma.

Idiopathic facial (Bell's palsy) palsy was the most common cause of facial palsy and accounts for over one third of all the cases surveyed in the present study. Peitersen ${ }^{18}$ reported a much higher incidence of idiopathic facial palsy; while Schaitkin et al ${ }^{19}$ and Austin et al ${ }^{20}$ had a similar incidence in their study. The second most common cause of facial palsy was found to be cerebro vascular accident (CVA). This is not surprising because the rate of cardiovascular disease in this part of the world is high ${ }^{21}$. Otitis media however recorded $76(12.8 \%)$ cases of facial palsy in this study which was comparable with the results by North Western University Medical School ${ }^{[22]}$ that facial palsy is rarely caused by otitis media.

Herpes zoster being a cause of facial palsy had an incidence of $1.3 \%$ which is contrary to the results of Sweeney and Gilden ${ }^{23}$ and Holland and Weiner ${ }^{24}$ who reported high incidences of facial palsy due to Herpes zoster. Similarly, incidence of facial palsy secondary to congenital cause is much less common in the present study and is similar to that reported by Ysunza et al ${ }^{25}$. Aron et al ${ }^{26}$ reported that otitis media being a cause of facial palsy is rarely encountered today which is not in line with the result of the present study. 


\section{Conclusion}

Bell's palsy remains the most common cause of facial (nerve) paralysis; generally, the incidence of facial palsy in Nigeria was high and similar to those reported abroad.

\section{References}

1. Kaylie DM, Wax MK, Weissman JL. Preoperative facial muscle imaging predicts final facial function after facial nerve grafting. American Journal of Neuroradiology. 2003; 24: 326-30.

2. Anderson RG. Facial nerve disorders. Select Read Plast Surg. 1991; 6: 1-34.

3. Savettieri G. Incidence and lifetime prevalence of Bell's palsy in two Sicilian municipalities. Sicilian neuro-epidemiologic study (SNES) group. Acta Neurol Scand. 1996; 94 (1): 71-5.

4. Nicoletti A. Lifetime prevalence of Bell's palsy in rural Bolivia: a door-to-door survey. Neuroepidemiology. 2002; 21 (2): 100-4.

5. Hawley C. Is it ever enough to die of old age? Age \& Ageing. 2003; 32: 454-86.

6. Holland NJ, Weiner GM. Recent developments in Bell's palsy. Clinical Review. 2004; 329: 553-7.

7. Al Ghamdi SA. Idiopathic facial nerve paralysis (Bell's palsy) in the Asir region. Ann Saudi Med. 1997; 17 (6): 609-11.

8. Hauser WA, Karnes WE, Annis J, et al. Incidence and prognosis of Bell's palsy in the population of Rochester, Minnesota. Mayo Clin Proc. 1971; 7: 436-40.

9. Katusic SK, Beard AM, Wiederhott WC. Incidence and clinical features and prognosis in Bell's palsy. Ann Neurol. 1986; 20: 622-7.

10. Ador KK, Byl FM, Hilsinger RL. The true nature of Bell's palsy: analysis of 1000 consecutive patients. Laryngoscope. 1978; 88: 787-801.

11. Bleicher JN, Hamiel S, Gengler JS, Antimarino J. A survey of facial paralysis: etiology and incidence. Ear Nose Throat J. 1996; 75: 355-8.

12. Noone J, Longe S. Bell's palsy. West J Med. 2000; 173: 266-8.

13. Morgan M, Nathwant D. Facial palsy and infection: the unfolding story. Clin Infect Dis. 1992; 14: 263-71.
14. Awda A, Ismail H, Al Rajeb S. Bell's palsy in the Eastern province of Saudi Arabia. Saudi Med J. 1992; 13: 534-7.

15. Jackson CG, von Doersten PG. The facial nerve: current trends in diagnosis, treatment, and rehabilitation. Med Clin North Am. 1999; 83: 179-95.

16. Ganong WF. Review of medical physiology. $18^{\text {th }}$ ed. Connecticut. Appleton and Lange, 1993.

17. Ahmed A. When is facial paralysis Bell palsy? Current diagnosis and treatment. Cleveland Clinic Journal of Medicine. 2005; 72 (5): 398-401.

18. Peitersen E. Bell's palsy: the spontaneous course of 2,500 peripheral facial nerve palsies of different etiologies. Acta Otolaryngol Suppl. 2002; 549: 4-30.

19. Schaitkin B, May M, Klein S. Office evaluation of the patient with facial palsy: differential diagnosis and prognosis. In: May M, Schaitkin B, eds. The Facial Nerve. 2nd ed. New York: Theime, 2000: pp179 -212.

20. Austin JR, Peskind SP, Austin SG, Rice DH. Idiopathic facial nerve paralysis: a randomized double blind controlled study of placebo versus prednisolone. Laryngoscope. 1993; 103: 1326.

21. Adedoyin RA, Adesoye AT. Incidence and pattern of cardiovascular disease in a Nigerian teaching hospital. Tropical Doctor 2005; 35 (2): 104-104(1).

22. Hain R. Bell's palsy. Neurology. North Western University Medical School (2001). Retrieved: http: / / www.neuro.nwu.edu/meded / CRANIAL/bells.html

23. Sweeney CJ, Gilden DH. Ramsay Hunt syndrome. J Neurol Neurosurg Psychiatry. 2001; 71: 149 .

24. Holland NJ, Weiner GM. Recent developments in Bell's palsy. BMJ. 2004; 329: 553-7.

25. Ysunza A, Inigo F, Rojo P . Congenital facial palsy and crossed facial nerve grafts: age and outcome. Int J Pediatr Otorbinolaryngol. 1996; 36 (2): 125-36.

26. Aron P. Facial Palsy with acute otitis media. Otolaryngology. 2005; 132 (2): 327-9. 